\section{Neil Roos}

Professor, Department of History, University of the Free State,

Email: RoosND@ufs.ac.za

DOI: https://dx.doi. org/10.18820/24150509/

SJCH44.v2.Intro

ISSN 0258-2422 (Print) ISSN 2415-0509 (Online)

Southern Journal for Contemporary History 2019 44(2):1-3

(c) Creative Commons With Attribution (CC-BY)

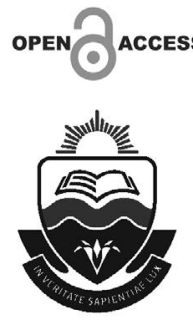

\section{TURNS, TRENDS AND NEW DIRECTIONS: THE SOUTHERN JOURNAL FOR CONTEMPORARY HISTORY}

Recently I have assumed editorship of the Journal for Contemporary History, housed at the University of the Free State, and this announcement is intended to introduce the new editorial team and also to signal some major changes in the Journal's editorial direction.

The Journal for Contemporary History has been in existence since 1975 , has carried more than 760 articles and 250 book reviews across 94 issues, and has had five previous editors. It published what former editor Andre Wessels described as "more traditional contemporary" history on themes like general elections, military history, history teaching and increasingly, liberation history focusing on subSaharan Africa. Since about 2005, the journal drew heavily on articles from the fields of international relations and political science. Over the course of its long history, the Journal for Contemporary History has published many articles which might otherwise not have seen the light of day, articles that might themselves constitute something of an archive.

However, as the big streams of the discipline shift direction, so too must the Journal if it is to remain relevant and reflect something of where the discipline of history finds itself today. While the focus has been on "more traditional contemporary history", we aim to solicit essays from the margins of the discipline and its historiographic frontier, and from disciplines adjacent to history.

One of the first tasks which we are undertaking is to change the name of the Journal in order to clearly distinguish it from the older, internationalrecognised Journal of Contemporary History. 
We propose to rename it the Southern Journal for Contemporary History, although this may take an issue or two to accomplish. A new name must be more than cosmetic, and should signal a new focus, notably an intellectual grounding in the idea of the global South. In light of this consideration we will take papers with a geographical or comparative focus beyond sub-Saharan Africa. While in practice, most articles will probably concentrate on Southern Africa, the new orientation could open the way for submissions from other parts of the South, enable theoretical and comparative engagement beyond the Southern African region, and potentially enrich current debates around decolonisation. In light of the Journal's intellectual commitment to the South, it is only right that this be matched by a political commitment to the free circulation of knowledge, and the Journal will be re-launched on an open access platform. Recognising that compelling historical insights come from scholars working outside of the formal ambit of the discipline, the Journal welcomes submissions from outside of history, with one proviso - that they are grounded in the unique disciplinary feature of history, namely, the study of change over time. We do, moreover, seek papers that are bottom up, go beyond elite representations and narratives, and which, even if they are not necessarily concentrated on "politics", pose questions directly to the realms of power.

The re-launched Journal will include a section for shorter review essays (dealing, for instance, with regional or comparative historiographies of any number of topics; the oeuvre of major scholars and commentators on the contemporary history of the global South; or, for that matter, what constitutes "the contemporary"). Providing a platform for such ventures into historiography, review and theory, would further mark the Journal's unique identity. Prof. Tinashe Nyamunda (Tinashe.nyamunda.spu.ac.za) will edit this section.

The Journal is open to publishing articles from some of the following fields:

- Race, ethnicity and gender

- Sameness

- Ecology, the environment and animals

- Histories of the everyday

- Childhood and youth

- Education

- Medicine and healing

- Non-elite histories of knowledge

- Histories of words 
- $\quad$ Non-elite perspectives on states, borders and citizenship

- $\quad$ Arts and culture

- Religion and the supernatural

- $\quad$ Sport, travel and leisure

We are presently re-configuring the editorial board to include external members who are both historians and well-versed in the theoretical notion of "the South".

What is most important in transforming the Journal, however, is cultivating a new pool of authors and reviewers, and we are especially keen to invite postdoctoral and other early career scholars to consider submitting essays to the Journal. In turn, we will be working closely with reviewers to ensure that their comments and suggestions are helpful, supportive and developmental.

We will be on Facebook and other social media (not yet, but soon). If you have ideas, suggestions or queries, please don't hesitate to contact Tinashe (Tinashe.nyamunda.spu.ac.za) or myself (RoosND@ufs.ac.za). With your participation we hope to transform the Journal into a publication that is bold, provocative, innovative and willing to take risks, by extending outwards epistemological, historiographic and methodological frontiers. 